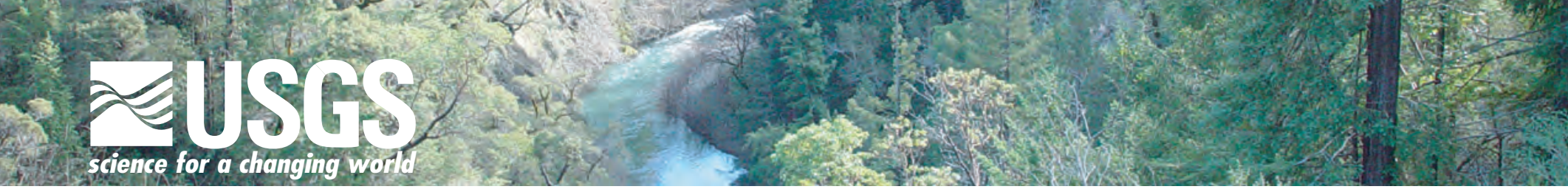

\title{
Biology and Invasive Species in the Western U.S.
}

The diversity of environments that characterizes the West is responsible for the region's rich biological heritage. This ecological diversity also means that opportunities for invasive species are many, varied, and complex. Island ecosystems are notoriously vulnerable to invaders as demonstrated in Hawaii and West Coast offshore islands. Aquatic invaders impose high economic and environmental costs in systems as varied as San Francisco Bay and desert springs in the Great Basin. Although the West's arid and montane ecosystems may seem resistant to plant and animal invaders, we now know that exotic species have altered physical processes related to fire and hydrology in a manner favoring further expansion and persistence of invaders. Natural resource managers value analytical, mapping, and genetics tools developed by USGS scientists to monitor invasive species and help conserve biological systems. USGS biologists conduct research to assist land and water managers' efforts to control invasive species and restore natural systems. Throughout the West, the USGS carries out studies for early detection and rapid assessment of invaders. The following are some examples of how the USGS is making a difference in the western United States.

\section{Islands in the Incoming Tide}

Introduction of invasive plant and animal species threatens to damage Pacific island ecosystems and inflict high economic cost. Because native island species often lack resis-

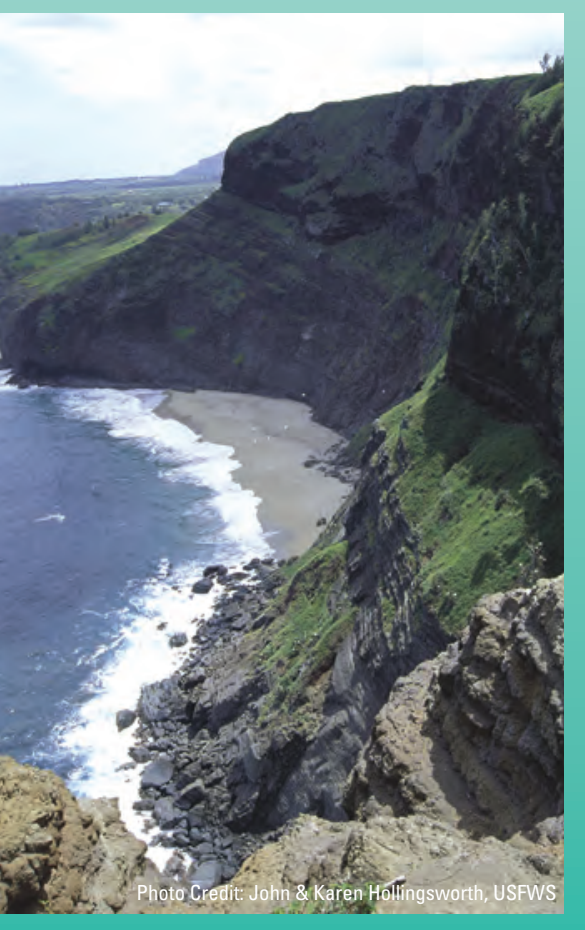

U.S. Department of the Interior

U.S. Geological Survey

\section{Biological Science Capabilities}

- Development of tools to analyze and map data

$\checkmark$ Development of genetic probes for rapid detection

$\checkmark$ Inventory and monitoring system development

$\checkmark$ Biology of species ranging from microbes to large vertebrates

$\checkmark$ Ecosystem science and restoration science

partners to develop tools for reducing species introductions, to develop collaborative survey methods for detecting invasions, and to establish mechanisms for evaluating the effectiveness of prevention measures.

\section{Invaders Find Their Way to Alaska (With Help)}

Historically, Alaska's National Parks have been nearly free of exotic species, but the rate of alien plant invasion is increasing rapidly. As in other places in the West, the USGS is conducting comprehensive studies in Alaska National Park Service units for early detection and rapid assessment of invaders. Results are available in online databases for use by resource managers. Scientists in Alaska have found that remote units with few visitors and limited access have near-pristine conditions. In contrast, parks with heavier visitation and easier access demonstrate a widespread occurrence of non-native plants in disturbed areas. USGS scientists are testing methods for early detection and rapid eradication in Denali National Park, as well as methods to identify factors

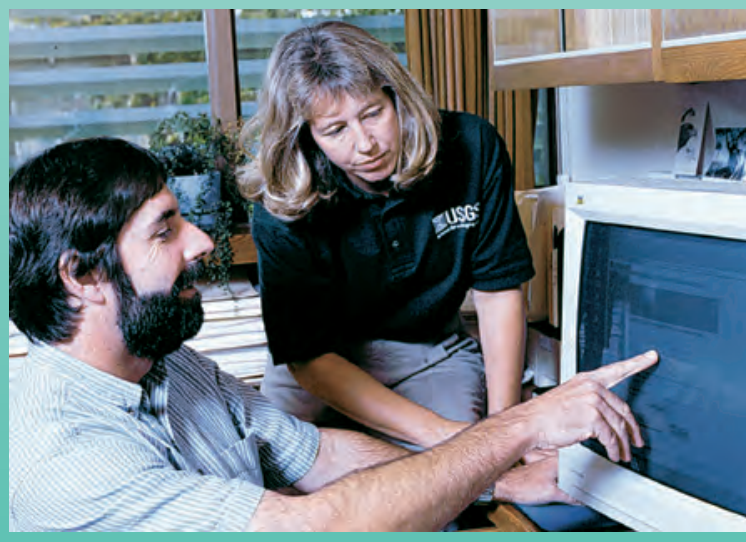
that predict the potential for further spread.

\section{An Invasive Plant Provides Habitat for an Endangered Species}

Tamarisk (saltcedar), an invasive, exotic shrub first introduced into the Southwest over 100 years ago, is now dominant 
